\title{
A Comprehensive RRM Domains Sequence Analysis from Nucleolin
} Proteins in Plants

\author{
Abou-Ellail, $M$. \\ Department of Genetics, Faculty of Agriculture and Natural Resources, Aswan Univer- \\ sity, Aswan, Egypt \\ Accepted for publication on: 7/9/2021
}

\begin{abstract}
In contrast to yeast and animal cells, plants contain two genes which is encoding to nucleolin proteins. A comprehensive protein sequence analysis revealed that the two RNA recognition motifs (RRM) domains are highly conserved and suggesting that the mechanisms and functions related to RNA contained RRMs are highly conserved in both plant nucleolin proteins sequences. Whereas Ribonucleoprotein 1 (RNP1) and Ribonucleoprotein 2 (RNP2) that are highly conserved sequences in RRMs from yeast and animal nucleolin, also my study confirmed that RNP1 and RNP2 sequences are conserved in plants. Nucleolin could use the same manner in the different species of plants and animals to achieve its function. Study of evolutionary relationships among nine different plant species revealed that monocots and dicots form two separated monophyletic group meaning that they composed of a collection of organisms, share a common evolutionary history and including the most recent common ancestor of all those organisms.
\end{abstract}

Keywords: Nucleolin proteins, evolutionary relationships, $R N A$ recognition motifs, $R i$ bonucleoprotein.

\section{Introduction}

The most copious protein in nucleolus is nucleolin which might play a major role in the multiple functions of the nucleolus. Moreover, its function in the cytoplasm and in the nucleoplasm, nucleolin has been participated in other processes, including repair, replication and recombination of DNA (Tuteja et al., 1995; Gregório et al., 2018 and Carvalho et al., 2021), pathogens internalization, replication, -resistance (Daniely and Borowiec, 2000; Nisole et al., 2002; Masiuk, 2010; Jiang et al., 2010), telomerase nucleolar localization (Khurts et al., 2004), growth and cell proliferation (Srivastava and Pollard, 1999), apoptosis (Zhang et al., 2010) and remodeling of chromatin (Angelov et al., 2006).

In plants, nucleolin proteins were described in alfalfa (Bogre et al., 1996), rice (Udomchalothorn et al., 2017) and pea (Tong et al., 1997). In alfalfa (Medicago sativa), seven cDNA clones were isolated from cDNA libraries and the sequencing of these clones indicated that at least three class encode to nucMs (nucleolin of Medicago sativa) genes. It appears to be the various transcripts encoded by different alleles, as a result of alfalfa is an autotetraploid species (Bogre et al., 1996). In pea, Southern blot analysis show only one copy gene of nucleolin protein, and northern blot analysis indicated that the labelled cDNA binds to unique RNA band, nearly the selfsame size $(2.3 \mathrm{~Kb})$ of the cDNA (Tong et al., 1997).

Most of the studies directed to understand nucleolin function in plants come from crucifer plant species. The first functional description 
of nucleolin protein came from studies in cauliflower (B. oleracea var. botrytis). Nucleolin from cauliflower that participated in processing of $45 \mathrm{~S}$ pre-rRNA, was joined to a large complex named ribonucleoprotein (Saez-Vasquez et al., 2004a, 2004b). In the other hand, it was shown that the genome of Arabidopsis thaliana (Col0) plants contains two genes encoding for nucleolin proteins: AtNUC-L1 and AtNUC-L2, located on chromosomes 1 and 3 respectively (Pontvianne et al., 2007 and Durut et al., 2014). During evolution, the nucleolin structure is highly conserved; it consists of three domains with same arrangement in animal and yeast: acidic domain, RNA recognition motifs domain (RRMs) and glycine-arginine rich domain (GAR). RRM domain was discovered in the late 1980s in the pre-mRNA splicing protein hnRNP (heterogeneous nuclear ribonucleoprotein) (Maris et al., 2005 and Carvalho et al., 2021).

The number of RRMs is similar in nucleolin from yeast, which possess two, compared to animals that contain four RRMs: Four in human (Srivastava et al., 1989); chicken (Maridor and Nigg, 1990); rat (Bourbon and Amalric, 1990); hamster (Lapeyre et al., 1985); mouse (Bourbon et al., 1988); and frog (Rankin et al., 1993); two RRMs in S. cerevisiae (Lee et al., 1992) and S. pombe (Gulli et al., 1995) and two in alfalfa (Bogre et al., 1996), Arabidopsis (Pontvianne et al., 2007) and pea (Tong et al., 1997). Interestingly, within the same nucleolin protein, the RRMs were less conserved in compared with the RRMs from various nucleolin protein. That means, for instance, the conservation between RRM1, RRM2, RRM3 and RRM4 from human is less compared with the conservation between RRM1 from human and RRM1 from chicken (Ginisty et al., 1999).

In animal, the central domain structure was analyzed precisely. The RRM consists of approximately 70100 amino acid sequence with a topology $\beta_{1} \alpha_{1} \beta_{2} \beta_{3} \alpha_{2} \beta_{4}$. The fold consists of one four-stranded antiparallel $\beta$-sheets, which arranged from left to right in $\beta_{4} \beta_{1} \beta_{3} \beta_{2}$, and two $\alpha$-helicases packed against the $\beta$-sheets, which are involved in the interaction with single-stranded RNA (Bouvet et al., 1997; Maris et al., 2005; Clery et al., 2008). The two highly conserved segments named Ribonucleoprotein 1 (RNP1) and Ribonucleoprotein 2 (RNP2) motifs are located in the central $\beta$-sheets, $\beta_{3}$ and $\beta_{1}$, respectively.

In animal, RNP1 consists of eight amino acids in arrangements $(\mathrm{R} \backslash \mathrm{K}) \mathrm{G}(\mathrm{F} \backslash \mathrm{Y})(\mathrm{G} \backslash \mathrm{A})(\mathrm{F} \backslash \mathrm{Y}) \mathrm{VX}(\mathrm{F} \backslash \mathrm{Y})$;

while the RNP2 contains six amino acids in arrangements (L\I) $(\mathrm{F} \backslash \mathrm{Y})$ $(\mathrm{V} \backslash \mathrm{I}) \quad(\mathrm{G} \backslash \mathrm{K})(\mathrm{G} \backslash \mathrm{N}) \mathrm{L}$. These motifs contain aromatic residues $\mathrm{Y}$ (Tyr); $\mathrm{H}$ (His), F (Phe); or Trp (W) at positions: 2 that is located in $\beta_{1}$-sheet in RNP2 and 3 and 5 located in the $\beta_{3^{-}}$ sheet in RNP1. The positions of aromatic residues are highly conserved, and they are participated in RNAbase-stacking interactions (Clery et al., 2008). The positions of aromatic residues are highly conserved, and they are known to be involved in base-stacking interactions with RNA (Rao et al., 2006). RNA binds to RRM by stacking of two specific bases of the 3' and the 5'nucleotides on an aromatic residue existent in in $\beta 3$ 
(RNP1-position 5) and $\beta 1$ (RNP2position 2), respectively (Allain et al., 2000; and Clery et al., 2008). The third aromatic residue that is found in $\beta 3$ (RNP1-position 3) possesses hydrophobic interactions with the sugar rings between the dinucleotides which are stacked to the positions 2 and 5 (Clery et al., 2008). In yeast each RRMs has also two highly conserved RNP1 and RNP2 (Kondo and Inouye; 1992 and Gulli et al., 1995).

\section{Materials and Methods}

Methods in sequence analysis

Plant nucleolin proteins (NUCL1 and NUC-L2) sequences were obtained from (http://blast.ncbi.nlm.nih.gov/Blast.cg i) and (http://ppdb.tc.cornell.edu) sites. Sequence alignments were carried out using Multalin program (Corpet, 1988). For study the secondary structure of RRMs from AtNUCL1 and AtNUC-L2 proteins, we used TMBpro program at site (http://www.ics.uci.edu/ baldig/tmb. html) (Randall et al., 2008).

Phylogenetic tree was generated with MEGA7 software (Kumar et al., 2016), performing 1000 bootstrap tests were used in Neighbor Joining method.

\section{Results}

\section{Study in nucleolin structure}

In eukaryotes, Nucleolin is a highly conserved structure that composes of three domains in the same arrangements: acicdic, RRMs and GAR domains. Plants and yeast nucleolin contain two RRMs in compare with four RRMs in animal nucleolin. To study the conservation of RRMs, we performed alignment for RRMs from nucleolin proteins from different species of plants, Arabidopsis thaliana, Oryza sativa indica, Oryza sativa japonica, Zea mays, Populus trichocarpa, Sorghum bicolor, Medicago sativa, Nicotiana tabacum and Pisum sativum as shown in Fig. 1. The alignment revealed the high conservation of all plant nucleolin RRMs. Moreover, the RRMs from different protein are more conserved than the same protein. For instance, the conservation among Nit NUC1 RRM1 (Nicotiana tabacum nucleolin 1 RRM1) and Nit_NUC1_RRM2 is less compared with the conservation between RRM1 from Nicotiana tabacum and RRM1 from Populus trichocarpa (Pot_NUC1_RRM1). Thus, as shown in Fig. 1 they are classified to two clusters, RRM1 cluster and RRM2 cluster. 

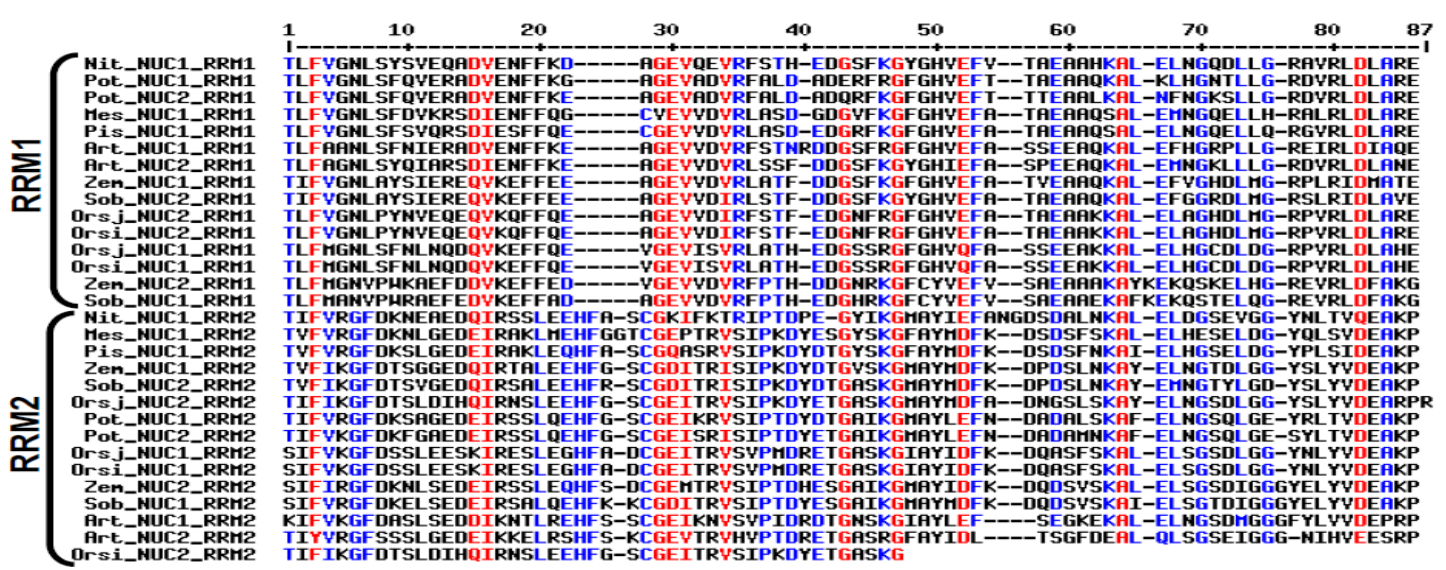

Figure 1: Alignment of different plant nucleolin RRMs by using Multalin program. Arabidopsis thaliana_Q9FVQ1(ArtNUC1), Q1PEP5 (ArtNUC2), Oryza sativa japonica_ Q6Z1C0 (OrsjNUC1), Q7XTT4 (OrsjNUC2), Oryza sativa indica_BGIOSIBCE026772 (OrsiUC1), BGIOSIBCE016635 (OrsiUC2), Sorghum bicolor_ Sb07g005510 (SobNUC1), Sb01g019710 (SobNUC2), Zea mays_FGP025 (ZemNUC1), FGT019 (ZemNUC2), Populus trichocarpa_002310655 (PotNUC1), 002307174 (PotNUC2), Medicago sativa_ T09648 (MesNUC-1), Nicotiana tabacum_ Q8LNZ4(NitNUC1) and Pisum sativum_T06458 (PsNUC-L1).

In another hand, the RRM domains alignment from different plant nucleolin proteins revealed that each RRM contains two highly conserved sequences, one of them: the highly conserved octamer sequences (RNP1) that is located in $\beta_{3}$ sheet and the other highly conserved hexamer sequences (RNP2) that is localized in $\beta_{1}$ sheet as shown in Fig. 3 and in Table 1. Excepting Oryza sativa indica nucleolin 2 (Ori_NUC-L2) that lacks RNP2 only from RRM2 (Table 1).
The presence of aromatic amino acids in RNPs is necessary for RRM binding to RNA (Clery et al., 2008). For study the position of the aromatic acid we performed alignment of RRMs from different plant nucleolin proteins. The positions of aromatic amino acids (Y (Tyr); H (His); F (Phe); or $\operatorname{Trp}(\mathrm{W})$ ) are conserved and they are found at positions 2 , in $\beta_{1}$ sheet in RNP2 and the other are present at positions 3 and 5 in $\beta_{3}$-sheet in RNP1 (Fig. 3 and Table 1).

Table 1. Alignment of the conserved RNP-1 and RNP-2 from two RRM motifs found in plants nucleolin proteins by using Multalin program.

\begin{tabular}{|l|c|c|c|c|}
\hline \multirow{2}{*}{} & \multicolumn{2}{|c|}{ RRM1 } & \multicolumn{2}{c|}{ RRM2 } \\
\cline { 2 - 5 } & RNP2 & RNP1 & RNP2 & RNP1 \\
\hline Nit_NUC-L1 & LFVGNL & KGYGHVEF & IFVRGF & KGMAYIEF \\
Mes_NUC-L1 & LFVGNL & KGFGHVEF & VFVRGF & KGFAYMDF \\
Pis_NUC-L1 & LFVGNL & KGFGHVEF & VFVRGF & KGFAYMDF \\
Zem_NUC-L1 & IFVGNL & KGFGHVEF & VFIKGF & KGMAYMDF \\
Orsi_NUC-L1 & LFMGNL & RGFGHVQF & IFVKGF & KGIAYIDF \\
Orsi_NUC-L2 & LFVGNL & RGFGHVEF & IFIKGF & KGMAYMDF \\
Art_NUC-L1 & LFAANL & RGFGHVEF & IFVKGF & KGIAYLEF \\
Art_NUC-L2 & LFAGNL & KGYGHIEF & IYVRGF & RGFAYIDL \\
Zem_NUC-L2 & LFMGNV & KGFCYVEF & IFIRGF & KGMAYIDF \\
Sob_NUC-L1 & LFMANV & KGFCYVEF & IFVRGF & KGMAYMDF \\
Orsi_NUC-L1 & LFMGNL & RGFGHVQF & IFVKGF & KGIAYIDF \\
Sob_NUC-L2 & IFVGNL & KGYGHVEF & VFIKGF & KGMAYMDF \\
Orsi_NUC-L2 & LFVGNL & RGFGHVEF & IFIKGF & ............ \\
Pot_NUC-L1 & LFVGNL & RGFGHVEF & IFVRGF & KGMAYLEF \\
Pot_NUC-L2 & LFVGNL & KGFGHVEF & IFVKGF & KGMAYLEF \\
Consensus & LFVGNL & KGFGHVEF & IFVKGF & KGMAYMDF \\
\hline
\end{tabular}


In topology study of RRM1, RRM2 and their separated region (linker), we observed that there are four $\beta$-sheets separated with two $\alpha$-helicases $\left(\beta_{1} \alpha_{1} \beta_{2} \beta_{3} \alpha_{2} \beta_{4}\right)$ in each RRM as shown in Fig. 3. Moreover, the linker is longer in AtNUC-L1 (29bp) than AtNUC-L2 (21bp).
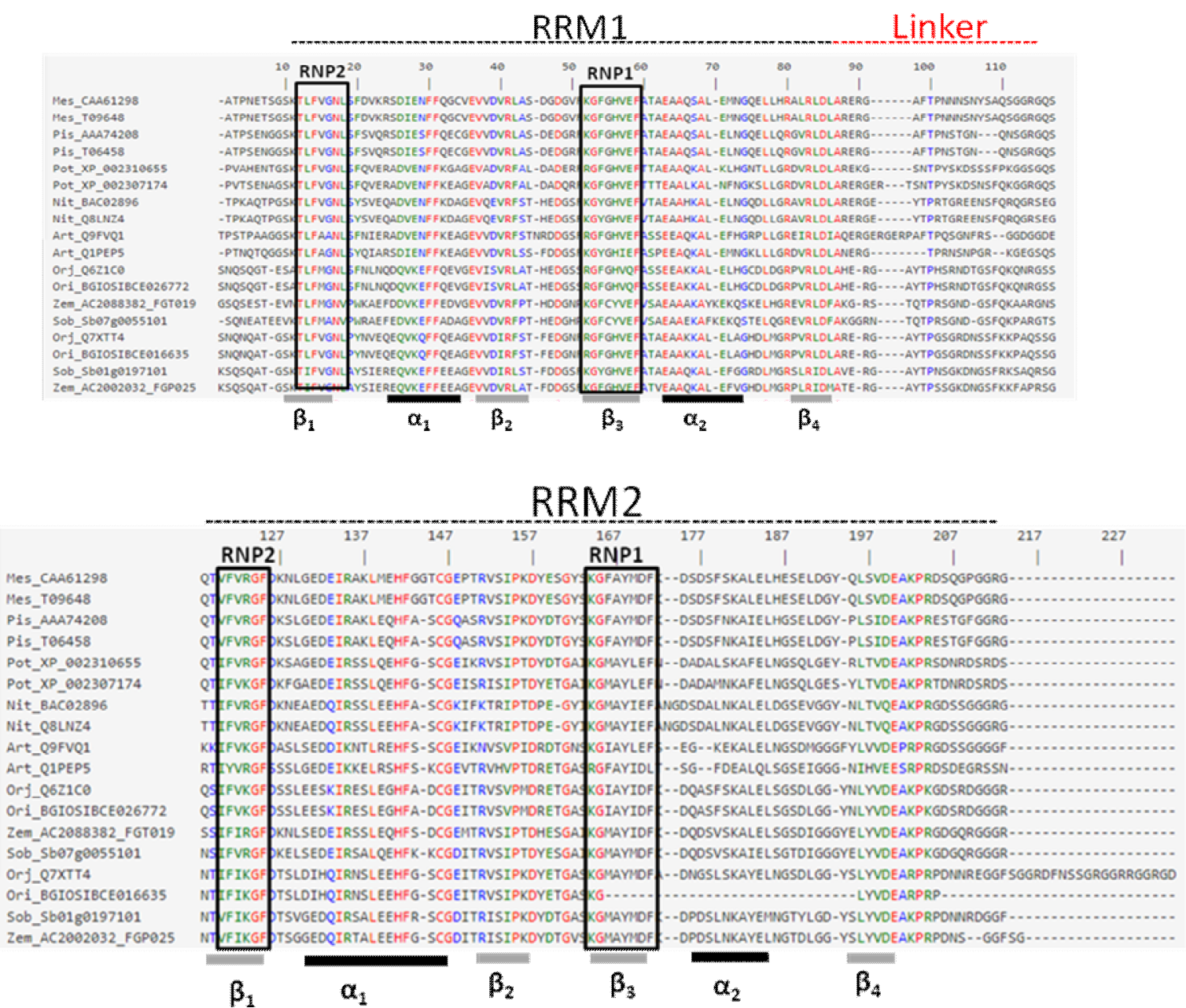

Figure 3. Amino acid sequences alignment (ClustalW) of nucleolin protein RRM1 and RRM2 from Pisum sativum, Populus trichocarpa, Nicotiana tabacum, Arabidopsis thaliana (Art), Oryza sativa japonica, Medicago sativa, Zea mays and Sorghum bicolor, Oryza sativa indica. Whereas, the black, red and gray dashed lines correspond to RRM1, linker and RRM2, respectively. Black boxes refer to RNP1s and RNP2s in the two RRMs. RRM1 and RRM2 secondary structure elements are indicated below the sequences. Whereas black and gray lines represent a-helices and b-sheets

\section{Evolutionary relationships of RRM2s and RRM1s from different types of nucleolin from plants}

To study of evolutionary relationships among nine types (Arabidopsis thaliana, Oryza sativa japonica, Zea mays, Oryza sativa indi- ca, Populus trichocarpa, Medicago sativa, Sorghum bicolor, Nicotiana tabacum and Pisum sativum) of plants depends on amino acid sequences of RRM1s and RRM2s from different types of nucleolin. The history of evolution was deduced using 
the Neighbor-Joining method as shown in phylogenetic tree (Figure 4). By analysis of phylogenetic tree, the monocotyledon and dicotyledon sequences were arranged in two separated tight groups at the branch tips. In dicot. group, the two nuc-11 and nuc-12 are clustered on the same branch but in monocot. nuc-11 from each Oryza sativa japonica and Oryza sativa indica; and Sorghum bicolor and Zea mays are on one branch, individually that is the same for nuc-12 from monocot. plants.

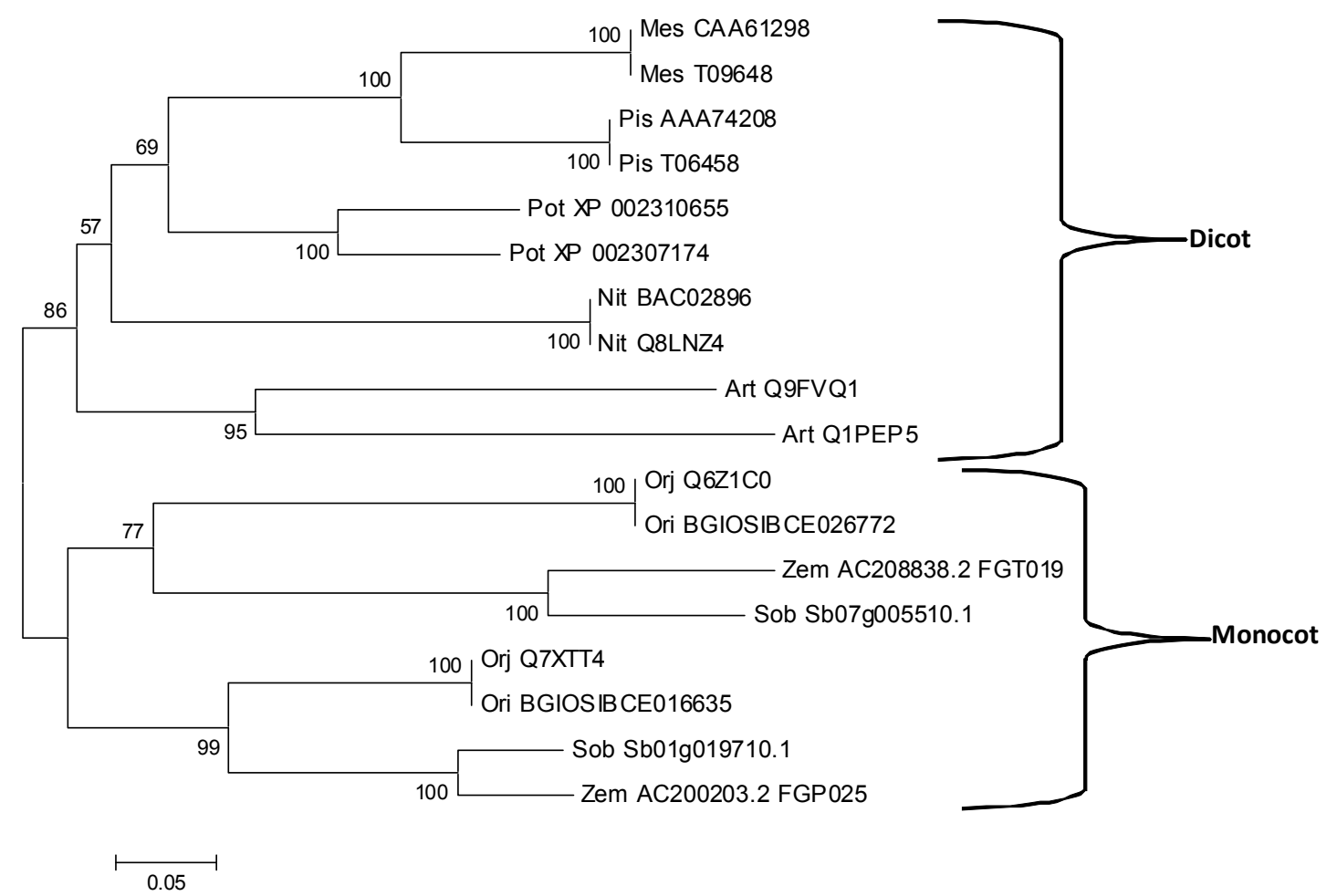

Fig 4. Phylogenetic tree of different plants depends on their RRMs of nucleolin proteins using Neighbor Joining method. nucleolin proteins schematic from Arabidopsis thaliana, Q9FVQ1(AtNUC-L1) and Q1PEP5 (AtNUC-L2), Oryza sativa japonica, Q6Z1C0 (OsjNUC-L1) and Q7XTT4 (OsjNUC-L2); Oryza sativa indica, BGIOSIBCE026772 (OsjNUC-L1) and BGIOSIBCE016635 (OsjNUC-L2), Sorghum bicolor, Sb07g005510 (SbNUC-L1), and Sb01g019710 (SbNUC-L2); Zea mays FGP025 (ZmNUC-L1) and FGT019 (ZmNUC-L2), Populus trichocarpa, 002310655 (PtNUC-L1) and 002307174 (PtNUC-L2), Medicago sativa, T09648 (MsNUC-L1), Nicotiana tabacum Q8LNZ4 (NtNUC-L1), Pisum sativum T06458 (PsNUC-L1).

\section{Discussion}

In plants and animal, RNArecognition motif (RRM) structure is conserved during the evolution. Whereas RNP1 and RNP2 that are highly conserved in RRMs from yeast and animal nucleolin, also they are conserved in plants. The conservation is in their positions and sequences, where the aromatic amino acids are localized in RNP2 (position 2) and in RNP1 (positions 3 and 5). It is similar as in animal and yeast, the RNP1 and 
RNP2 exist in $\beta_{3}$-sheet and $\beta_{1}$-sheet, respectively. Also, the arrangements of $\beta$ and $\alpha$ sheets are quietly like that finding in animal nucleolin (Maris et al., 2005 and Clery et al., 2008). Binding of RNA to the RRM by stacking of two certain bases of the 3 'and the 5' nucleotides on an aromatic residue found in $\beta 3$ (position 5 in RNP1) and in $\beta 1$ (position 2 in RNP2), respectively (Allain et al., 2000 and Clery et al., 2008). The third aromatic ring that is usually located in $\beta 3$ (position 3 of RNP1) has often hydrophobic interactions with the sugar rings between the dinucleotides which are stacked to the positions 2 and 5 (Clery et al., 2008). It seems to be nucleolin use the same manner in the different species of plants and animals to achieve its function.

Plants show two genes encoding nucleolin proteins. Both proteins are structurally conserved and have the tripartite organization characteristic of nucleolin: i.e. the acidic, the RRM and the GAR domains. Protein sequence analysis revealed that the two RRM domains are highly conserved and suggests that the mechanisms and functions related to RNA are conserved in both plant nucleolin sequences. Study of evolutionary relationships among nine types revealed that monocots and dicots form two separated monophyletic group meaning that they composed of a collection of organisms, share a common evolutionary history and including the most recent common ancestor of all those organisms (Slobodian and Pastana, 2020).
References

Allain, F.H., Bouvet, P., Dieckmann, T., and Feigon, J. (2000). Molecular basis of sequence-specific recognition of pre-ribosomal RNA by nucleolin. Embo J 19, 6870-6881.

Angelov, D., Bondarenko, V.A., Almagro, S., Menoni, H., Mongelard, F., Hans, F., Mietton, F., Studitsky, V.M., Hamiche, A., Dimitrov, S., and Bouvet, P. (2006). Nucleolin is a histone chaperone with FACTlike activity and assists remodeling of nucleosomes. Embo J 25, 16691679.

Bogre, L., Jonak, C., Mink, M., Meskiene, I., Traas, J., Ha, D.T., Swoboda, I., Plank, C., Wagner, E., Heberle-Bors, E., and Hirt, H. (1996). Developmental and cell cycle regulation of alfalfa nucMs1, a plant homolog of the yeast Nsr1 and mammalian nucleolin. Plant Cell 8, 417-428.

Bourbon, H.M., and Amalric, F. (1990). Nucleolin gene organization in rodents: highly conserved sequences within three of the 13 introns. Gene 88, 187-196.

Bourbon, H.M., Lapeyre, B., and Amalric, F. (1988). Structure of the mouse nucleolin gene. The complete sequence reveals that each RNA binding domain is encoded by two independent exons. J Mol Biol 200, 627-638.

Bouvet, P., Jain, C., Belasco, J.G., Amalric, F., and Erard, M. (1997). RNA recognition by the joint action of two nucleolin RNA-binding domains: genetic analysis and structural modeling. Embo J 16, 5235-5246.

Carvalho S. L., Gonçalves N., Fonseca N.A. and Moreira N. (2021). Cancer Stem Cells and Nucleolin as Drivers of Carcinogenesis. Pharmaceuticals (Basel). 14(1): 60. 
Clery, A., Blatter, M., and Allain, F.H. (2008). RNA recognition motifs: boring? Not quite. Curr Opin Struct Biol 18, 290-298.

Corpet, F. (1988). Multiple sequence alignment with hierarchical clustering. Nucleic Acids Res 16, 10881-10890.

Daniely, Y., and Borowiec, J.A. (2000). Formation of a complex between nucleolin and replication protein $\mathrm{A}$ after cell stress prevents initiation of DNA replication. J Cell Biol 149, 799-810.

Durut N, Abou-Ellail M, Pontvianne F, Pontvianne F., Das S., Kojima H., et. al., (2014): A duplicated NUCLEOLIN gene with antagonistic activity is required for chromatin organization of silent $45 \mathrm{~S}$ rDNA in Arabidopsis. Plant Cell 26, 1330 1344.

Ginisty, H., Sicard, H., Roger, B., and Bouvet, P. (1999). Structure and functions of nucleolin. J Cell Sci 112 (Pt 6), 761-772.

Gregório A. C., Lacerda M., Figueiredo P., Simões S., Dias S., Moreira J. N. (2018). Meeting the needs of breast cancer: A nucleolin's perspective. Critical Reviews in Oncology/Hematology; 125:89-101.

Gulli, M.P., Girard, J.P., Zabetakis, D., Lapeyre, B., Melese, T., and Caizergues-Ferrer, M. (1995). gar2 is a nucleolar protein from Schizosaccharomyces pombe required for 18S rRNA and 40S ribosomal subunit accumulation. Nucleic Acids Res 23, 1912-1918.

Jiang, Y., Li, Z., and Nagy, P.D. (2010a). Nucleolin/Nsrlp binds to the 3' noncoding region of the tombusvirus RNA and inhibits replication. Virology 396, 10-20.

Khurts, S., Masutomi, K., Delgermaa, L., Arai, K., Oishi, N., Mizuno, H., Hayashi, N., Hahn, W.C., and Murakami, S. (2004). Nucleolin inter- acts with telomerase. J Biol Chem 279, 51508-51515.

Kondo, K., and Inouye, M. (1992). Yeast NSR1 protein that has structural similarity to mammalian nucleolin is involved in pre-rRNA processing. J Biol Chem 267, 1625216258.

Kumar S., Stecher G. and Tamura K. (2016). MEGA7: Molecular Evolutionary Genetics Analysis version 7.0 for bigger datasets. Molecular Biology and Evolution 33:1870-1874

Lapeyre, B., Caizergues-Ferrer, M., Bouche, G., and Amalric, F. (1985). Cloning of cDNA encoding a $100 \mathrm{kDa}$ nucleolar protein (nucleoline) of Chinese hamster ovary cells. Nucleic Acids Res 13, 5805-5816.

Lee, W.C., Zabetakis, D., and Melese, T. (1992). NSR1 is required for prerRNA processing and for the proper maintenance of steady-state levels of ribosomal subunits. Mol Cell Biol 12, 3865-3871.

Maridor, G., and Nigg, E.A. (1990). cDNA sequences of chicken nucleolin/C23 and NO38/B23, two major nucleolar proteins. Nucleic Acids Res 18, 1286.

Maris, C., Dominguez, C., and Allain, F.H. (2005). The RNA recognition motif, a plastic RNA-binding platform to regulate posttranscriptional gene expression. Febs J 272, 2118-2131.

Masiuk, M. (2010). NucleolinCharacteristics of Protein and its Role in Biology of Cancers and Viral Infections. Advances in Cell Biology 1, 1-19.

Nisole, S., Said, E.A., Mische, C., Prevost, M.C., Krust, B., Bouvet, P., Bianco, A., Briand, J.P., and Hovanessian, A.G. (2002). The anti-HIV pentameric pseudopeptide HB-19 binds the C-terminal end of 
nucleolin and prevents anchorage of virus particles in the plasma membrane of target cells. J Biol Chem 277, 20877-20886.

Pontvianne, F., Matia, I., Douet, J., Tourmente, S., Medina, F.J., Echeverria, M., and Saez-Vasquez, J. (2007). Characterization of AtNUC-L1 reveals a central role of nucleolin in nucleolus organization and silencing of AtNUC-L2 gene in Arabidopsis. Mol Biol Cell 18, 369-379.

Randall, A., Cheng, J., Sweredoski, M., and Baldi, P. (2008). TMBpro: secondary structure, beta-contact and tertiary structure prediction of transmembrane beta-barrel proteins. Bioinformatics 24, 513-520.

Rankin, M.L., Heine, M.A., Xiao, S., LeBlanc, M.D., Nelson, J.W., and DiMario, P.J. (1993). A complete nucleolin cDNA sequence from Xenopus laevis. Nucleic Acids Res $21,169$.

Rao, J.N., Neumann, L., Wenzel, S., Schweimer, K., Rosch, P., and Wohrl, B.M. (2006). Structural studies on the RNA-recognition motif of NELF E, a cellular negative transcription elongation factor involved in the regulation of HIV transcription. Biochem J 400, 449456.

Saez-Vasquez, J., Caparros-Ruiz, D., Barneche, F., and Echeverria, M. (2004a). Characterization of a crucifer plant pre-rRNA processing complex. Biochem Soc Trans 32, 578-580.

Saez-Vasquez, J., Caparros-Ruiz, D., Barneche, F., and Echeverria, M. (2004b). A plant snoRNP complex containing snoRNAs, fibrillarin, and nucleolin-like proteins is competent for both rRNA gene binding and pre-rRNA processing in vitro. Mol Cell Biol 24, 7284-7297.
Srivastava, M., and Pollard, H.B. (1999). Molecular dissection of nucleolin's role in growth and cell proliferation: new insights. Faseb J 13, 1911-1922.

Srivastava, M., Fleming, P.J., Pollard, H.B., and Burns, A.L. (1989). Cloning and sequencing of the human nucleolin cDNA. FEBS Lett 250, 99-105.

Tong, C.G., Reichler, S., Blumenthal, S., Balk, J., Hsieh, H.L., and Roux, S.J. (1997). Light regulation of the abundance of mRNA encoding a nucleolin-like protein localized in the nucleoli of pea nuclei. Plant Physiol 114, 643-652.

Tuteja, N., Huang, N.W., Skopac, D., Tuteja, R., Hrvatic, S., Zhang, J., Pongor, S., Joseph, G., Faucher, C., Amalric, F., and et al. (1995). Human DNA helicase IV is nucleolin, an RNA helicase modulated by phosphorylation. Gene 160 , 143-148.

Udomchalothorn T., Plaimas K., Sripinyowanich S., Boonchai C., Kojonna T., Chutimanukul P., Comai Luca, Buaboocha T. and Chadchawan S., (2017). OsNucleolin1-L Expression in Arabidopsis Enhances Photosynthesis via Transcriptome Modification under Salt Stress Conditions. Plant Cell Physiol. 58(4): 717-734.

Wang Y., J. Guan H. Wang D. Leeper and G. Iliakis. (2001). Regulation of DNA replication after heat shock by replication protein Anucleolin interactions. J. Biol. Chem. 276:20579-20588.

Zhang, B., Wang, H., Jiang, B., Liang, P., Liu, M., Deng, G., and Xiao, X. (2010). Nucleolin/C23 is a negative regulator of hydrogen peroxide-induced apoptosis in HUVECs. Cell Stress Chaperones 15, 249257. 
تحليل شامل لتتابعات منطقة الـ RRM في بروتينات النيوكليولين في النباتات

محمد أبو الليل

قسم الور اثة، كلية الزر اعة و المو ارد الطبيعية، جامعة أسوان، أسوان، مصر

تحنوي النباتات، على عكس الخلايا الحيو انية و الخميرة، على إثثين من الجينات التي تثشفر

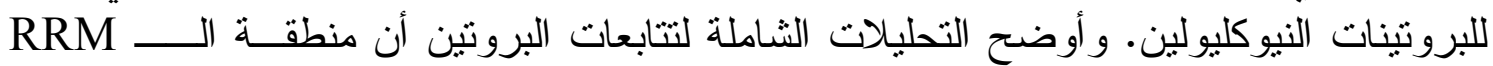

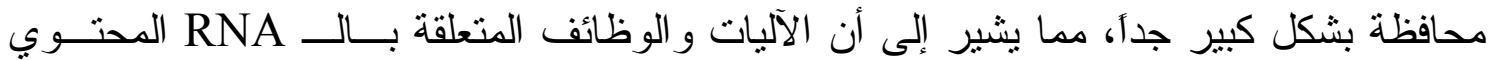

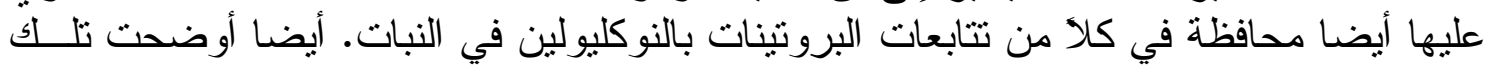

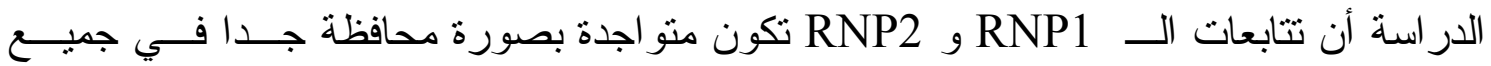

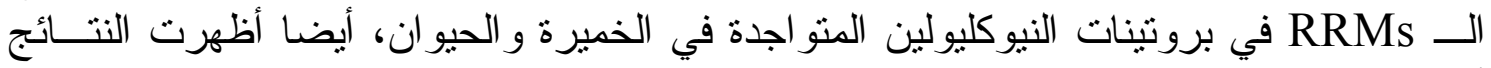

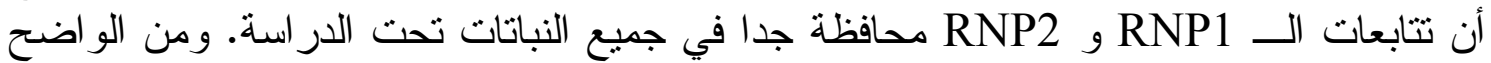

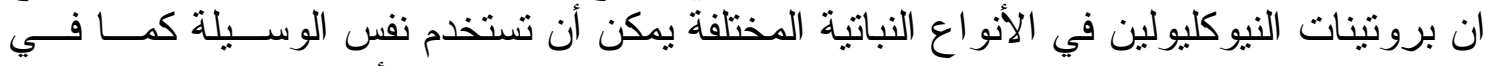

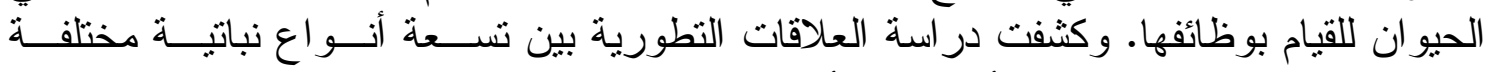

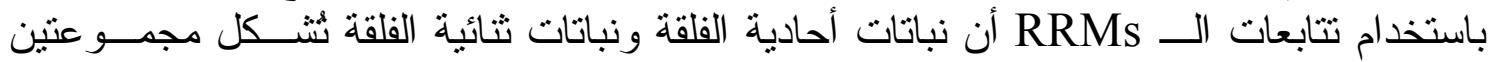

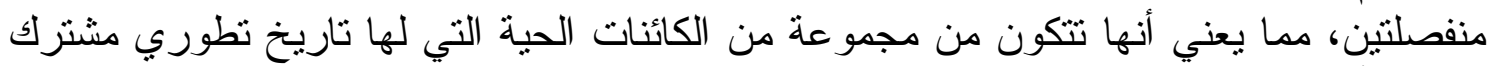
وتتثل أحدث سلف مشترك لجميع هذه الكائنات الحية. 